\title{
Corrigendum: Unexpected Variation in Neuroanatomy among Diverse Nematode Species
}

\author{
Ziduan Han ${ }^{1}$, Stephanie Boas ${ }^{1}$ and Nathan E. Schroeder ${ }^{1,2 *}$ \\ ${ }^{1}$ Department of Crop Sciences, University of Illinois at Urbana-Champaign, Urbana, IL, USA, ${ }^{2}$ Neuroscience Program, \\ University of Illinois at Urbana-Champaign, Urbana, IL, USA
}

Keywords: invertebrate, amphid, phasmid, Pratylenchus, Meloidogyne, Heterodera, Heterorhabditis, heterochrony

\section{A corrigendum on}

Unexpected Variation in Neuroanatomy among Diverse Nematode Species by Han, Z., Boas, S., and Schroeder, N. E. (2016). Front. Neuroanat. 9:162. doi: 10.3389/fnana.2015.00162

The complete number of ventral nerve cord (VNC) neurons for Ascaris suum should be given as 72 in the introduction and Table 1 . The 55 VNC neurons listed in our publication refers only to the five repeating segments of 11 neurons as discussed in Stretton et al. (1978). An additional 17 neurons are found outside of these repeating segments within the A. suum VNC (see Stretton and Maule, 2013 for review).

This correction does not impact the results or the conclusions reached in our study.

\section{AUTHOR CONTRIBUTIONS}

\section{OPEN ACCESS}

Edited and reviewed by: Agustín González, Universida Complutense de Madrid,

*Correspondence:

Nathan E. Schroeder nes@illinois.edu

Received: 06 April 2016 Accepted: 21 April 2016

Published: 03 May 2016

Citation:

Han Z, Boas S and Schroeder NE (2016) Corrigendum: Unexpected Variation in Neuroanatomy among Diverse Nematode Species.

Front. Neuroanat. 10:52. doi: 10.3389/fnana.2016.00052
All authors listed, have made substantial, direct and intellectual contribution to the work, and approved it for publication.

\section{ACKNOWLEDGMENTS}

We are thankful to Dr. Antony Stretton for noting the correct number of VNC neurons in A. suum.

\section{REFERENCES}

Stretton, A. O. W., Fishpool, R. M., Southgate, E., Donmoyer, J. E., Walrond, J. P., Moses, J. E., et al. (1978). Structure and physiological activity of the motoneurons of the nematode Ascaris. Proc. Natl. Acad. Sci. U.S.A. 75, 3493-3497.

Stretton, A. O. W., and Maule, A. G. (2013) "The neurobiology of Ascaris and other parasitic nematodes," in Ascaris: The Neglected Parasite, ed Holland, C. (London, UK: Academic Press), 127-152.

Conflict of Interest Statement: The authors declare that the research was conducted in the absence of any commercial or financial relationships that could be construed as a potential conflict of interest.

Copyright $\odot 2016$ Han, Boas and Schroeder. This is an open-access article distributed under the terms of the Creative Commons Attribution License (CC BY). The use, distribution or reproduction in other forums is permitted, provided the original author $(s)$ or licensor are credited and that the original publication in this journal is cited, in accordance with accepted academic practice. No use, distribution or reproduction is permitted which does not comply with these terms. 